\title{
ICT-based adherence monitoring in kidney transplant recipients: a randomized controlled trial
}

Hee-Yeon Jung ${ }^{1}$, Yena Jeon ${ }^{2}$, Sook Jin Seong ${ }^{3}$, Jung Ju Seo ${ }^{1}$, Ji-Young Choi ${ }^{1}$, Jang-Hee Cho ${ }^{1}$, Sun-Hee Park', Chan-Duck Kim', Young-Ran Yoon ${ }^{3}$, Se-Hee Yoon ${ }^{4}$, Jong Soo Lee ${ }^{5}$ and Yong-Lim Kim ${ }^{1 *}$ (i)

\begin{abstract}
Background: Prior studies have explored the use of regular reminders to improve adherence among kidney transplant recipients (KTRs), but none have included real-time alarms about drug dosage, frequency, and interval. In the present study, we aimed to evaluate the efficacy and stability of an information and communication technology (ICT)-based centralized monitoring system for increasing medication adherence among Korean KTRs.

Methods: In this prospective, multicenter, randomized controlled study, enrolled KTRs were randomized to either the ICT-based centralized monitoring group or control group. The ICT-based centralized monitoring system alerted both patients and medical staff with texts and pill box alarms if there was a missed dose or a dosage/time error. We compared the two groups in terms of medication adherence and transplant outcomes over 6 months, and evaluated patient satisfaction with the ICT-based monitoring system.
\end{abstract}

Results: Among 114 enrolled KTRs, 57 were assigned to the ICT-based centralized monitoring group and 57 to the control group. The two groups did not significantly differ in mean adherence at each follow-up visit. The intrapatient variability of tacrolimus and mycophenolic acid levels, renal function, and adverse transplant outcomes did not differ between the intervention and control groups, or between the intervention group with feedback generation and the intervention group without feedback generation. Patients showed high overall satisfaction with the ICT-based centralized monitoring system, which significantly improved across the study period $(p=0.012)$.

Conclusions: Due to high baseline adherence, the ICT-based centralized monitoring system did not maximize medication adherence or enhance transplant outcomes among Korean KTRs. However, patients were highly satisfied with the system. Our results suggest that the ICT-based centralized monitoring system could be successfully applied in clinical trials.

Trial registration: ClinicalTrials.gov, NCT03136588. Registered 20 April 2017 - Retrospectively registered.

Keywords: Information and communication technology, Feedback, Adherence, Kidney transplantation

\footnotetext{
* Correspondence: ylkim@knu.ac.kr

'Division of Nephrology, Department of Internal Medicine, School of

Medicine, Kyungpook National University, Kyungpook National University

Hospital, Daegu 41944, South Korea

Full list of author information is available at the end of the article
}

(c) The Author(s). 2020 Open Access This article is licensed under a Creative Commons Attribution 4.0 International License, which permits use, sharing, adaptation, distribution and reproduction in any medium or format, as long as you give appropriate credit to the original author(s) and the source, provide a link to the Creative Commons licence, and indicate if changes were made. The images or other third party material in this article are included in the article's Creative Commons licence, unless indicated otherwise in a credit line to the material. If material is not included in the article's Creative Commons licence and your intended use is not permitted by statutory regulation or exceeds the permitted use, you will need to obtain permission directly from the copyright holder. To view a copy of this licence, visit http://creativecommons.org/licenses/by/4.0/. The Creative Commons Public Domain Dedication waiver (http://creativecommons.org/publicdomain/zero/1.0/) applies to the data made available in this article, unless otherwise stated in a credit line to the data. 


\section{Background}

Among kidney transplant recipients (KTRs), nonadherence to immunosuppressive medications is a major cause of antibody-mediated rejection, which leads to graft loss $[1,2]$. Immunosuppressant non-adherence also contributes to the increased healthcare costs [3] associated with acute rejection treatment, additional hospitalization, and re-dialysis. Therefore, it is crucial to monitor KTRs who require long-term pharmacotherapy, and prevent non-adherence.

Previous studies have reported that approximately 14$36 \%$ KTRs are non-adherent to immunosuppressive medications [4-6]. Medication non-adherence can be either intentional or unintentional. We hypothesized that unintentional forgetfulness regarding immunosuppressive medications in KTRs could be improved by continuous electronic monitoring of adherence, and by providing patients with reminder alarms from the information and communication technology (ICT)-based centralized monitoring system. Previous studies have attempted to improve medication adherence among KTRs by using technology-based adherence-promoting interventions [7-9]. Compared to prior investigations, the main methodologic difference in our present study is that we provided real-time alarms about both drug dose and interval, and used a smart pill box to determine adherence, including dose-taking adherence, dose-frequency adherence, frequency, and dose-interval adherence.

In the present study, we aimed to determine the efficacy and stability of an ICT-based centralized monitoring system with regards to improving adherence to immunosuppressive medication and transplant outcomes in KTRs.

\section{Methods}

\section{Study overview}

Details about the study protocol have been previously described [10]. Briefly, 114 KTRs who completed the informed consent form were registered and randomly assigned in a 1:1 ratio to the ICT-based centralized clinical trial monitoring group or the ambulatory follow-up group. The planned follow-up duration was 6 months. After randomization, both groups were scheduled to for 6 visits: at $4,8,12,16,20$, and 24 weeks. In the ICTbased centralized clinical trial monitoring group, both patients and the medical staff received feedback in the form of texts and pill box alarms in the event of a dosage/dosing time error or a missed dose.

\section{Feedback algorithms}

In the ICT-based centralized monitoring group, both participants and medical staff received feedback in the form of text message alarms regarding missed doses, misuse, or overuse of the medication. In the event of a missed immunosuppressant dose, the first violation generates feedback within $1 \mathrm{~h}$ at the break of the $\pm 3 \mathrm{~h}$ range from the fixed dosing time. If the dose is still not taken after the feedback, up to two additional texts are sent at a 30-min interval. Feedback was also sent within $1 \mathrm{~h}$ from the moment of recognition in the event of any discrepancy between the dosage taken and the dosage prescribed, and if a dose was taken outside of the allowed \pm $3 \mathrm{~h}$ dosing time range.

\section{Hypothesis and limitations}

We hypothesized that patients failed to take their medications due to unintentional forgetfulness, and that the ICT-based centralized monitoring system could improve medication adherence among KTRs. Notably, this system does not include a camera to record patients at the moment of medication ingestion and, therefore, cannot improve intentional non-adherence.

\section{Patient selection}

The patient inclusion criteria were as follows: age of $\geq 8$ years; underwent kidney transplantation $\geq 1$ month ago; maintained stable renal function after kidney transplantation, with an estimated glomerular filtration rate (eGFR) of $\geq 30 \mathrm{~mL} / \mathrm{min} / 1.73 \mathrm{~m}^{2}$; history of kidney transplantation only, with no other organ transplantations; use of tacrolimus, mycophenolic acid, and steroids for post-transplant immunosuppression; signed the informed consent form in compliance with due process; and capable of making office visits and participating in the trial in accordance with the protocol.

The patient exclusion criteria were as follows: refusal of the ICT-based centralized home monitoring; history of treatment for acute rejection within the past 3 months; active infectious disease; uncorrected ischemic heart disease; visual or auditory impairments that could affect use of the smart pill box; inability to provide fingerprint authentication of personal identity (e.g., due to adermatoglyphia); illiteracy; lack of smartphone and unable to receive text messages; and other investigatordetermined reasons that made participation in the clinical trial inappropriate.

\section{Primary outcomes}

The primary outcome was medication adherence. Dosetaking adherence, dose-frequency adherence, doseinterval adherence, and drug holidays were assessed based on the smart pill box data in the ICT-based centralized monitoring group, and based on the drug administration diary in the ambulatory follow-up group. Dose-taking adherence was calculated as (the number of pills taken over a certain time period/the number of pills prescribed over the same period) $\times 100 \%$. Dosefrequency adherence was calculated as (the number of 
days of correct daily dosing over a certain time period/ the number of days in the same period) $\times 100 \%$. Doseinterval adherence was calculated as (the number of correct dosing intervals over a certain time period/the number of days in the same period) $\times 100 \%$. A correct dosing interval was defined with a margin of $\pm 25 \%$. In this trial, the medication was to be taken twice daily, with a $12-\mathrm{h}$ dosing interval. Thus, the allowed dosing interval ranged from 9 to $15 \mathrm{~h}$. A drug holidays was calculated as (the number of days without taking the medication/the number of days in the same period) $\times 100 \%$.

\section{Secondary outcomes}

The secondary outcomes included transplant outcomes and patient satisfaction with the system. Trough levels of tacrolimus and mycophenolic acid, coefficient of variation $(\mathrm{CV})$ of drug levels, and eGFR were measured at 4 , $8,12,16,20$, and 24 weeks of follow-up. To determine within-patient variability in immunosuppressant trough levels, the CV (\%) was calculated as (the standard deviation/mean trough level of the immunosuppressant) $\times$ 100 [11]. Panel-reactive antibody (PRA) was assessed at baseline and at 24 weeks. At 12 weeks, we measured serum BK virus, which is a well-known etiologic agent of viral infection in KTRs [12]. To evaluate clinical outcome, we analyzed the development of biopsy-proven acute rejection (BPAR) and death-censored graft loss (DCGL) during follow-up. At 4 and 24 weeks, a patient satisfaction questionnaire was administered in the ICTbased centralized clinical trial monitoring group to determine whether the patients were satisfied with the system. This questionnaire is presented in additional file 1 . This questionnaire was conducted because patient reported outcomes, including satisfaction with the system, are important, and it is important to ensure that patients are willing to use the system in the future.

\section{Statistical analysis}

Between-group differences were tested by independent sample $t$-tests and chi-squared tests, as appropriate. The inter-group difference in immunosuppressant adherence was assessed using the $t$-test, and intra-group variation was analyzed with the paired $t$-test. Statistical analyses were performed using the SAS system for Windows, version 9.2 (SAS Institute Inc., Cary, NC). A $p$ value of $<0.05$ was considered statistically significant.

\section{Results \\ Study participants}

Figure 1 shows patient inclusion in a flowchart. A total of 114 KTRs were randomized 1:1 into the intervention group $(n=57)$ or control group $(n=57)$. After excluding patients who withdrew consent or dropped out, the final analyses included 51 KTRs in the intervention group and 54 in the control group. Table 1 shows the baseline characteristics of the included patients. The mean age was 49.9 years in the intervention group, and 49.0 years in the control group. Males comprised $60.8 \%$ of the intervention group, and $53.7 \%$ of the control group. Living donor KT had been performed in $47.1 \%$ of the intervention group, and $35.2 \%$ of the control group. The mean eGFR was 69.7 in the intervention group, and 74.3 in the control group.

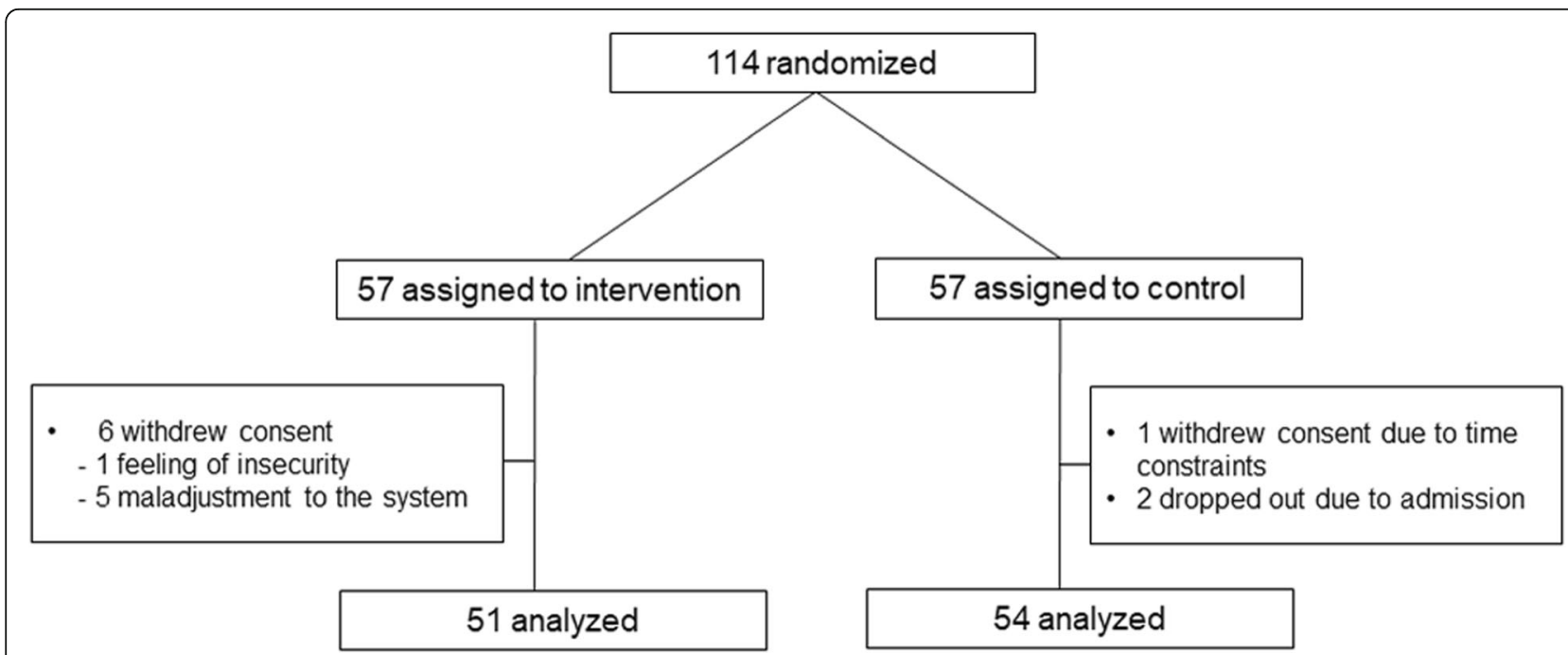

Fig. 1 Flow of participants inclusion. A total of 114 KTRs were randomized 1:1 into the intervention group $(n=57)$ or control group ( $n=57)$. After excluding patients who withdrew consent or dropped out, the final analyses included 51 KTRs in the intervention group and 54 in the control group 
Table 1 Baseline characteristics

\begin{tabular}{|c|c|c|}
\hline & Intervention $(n=51)$ & Control $(n=54)$ \\
\hline Age, years & $49.9 \pm 10.0$ & $49.0 \pm 12.2$ \\
\hline Male, $n(\%)$ & $31(60.8)$ & $29(53.7)$ \\
\hline \multicolumn{3}{|l|}{ Smoking, $n(\%)$} \\
\hline Non-smoker & $39(76.5)$ & $48(88.9)$ \\
\hline Ex-smoker & $8(15.7)$ & $6(11.1)$ \\
\hline Current smoker & $4(7.8)$ & $0(0)$ \\
\hline Time after KT, months & $30.7 \pm 19.8$ & $15.7 \pm 9.5$ \\
\hline \multicolumn{3}{|l|}{ Primary renal disease, $n(\%)$} \\
\hline Diabetes & $13(25.5)$ & $13(24.1)$ \\
\hline Non-diabetes & $38(74.5)$ & $41(75.9)$ \\
\hline Donor age, years & $46.0 \pm 12.6$ & $45.3 \pm 14.8$ \\
\hline Donor male, $n(\%)$ & $25(49.0)$ & $31(59.6)$ \\
\hline \multicolumn{3}{|l|}{ Donor type, $n(\%)$} \\
\hline Living & $24(47.1)$ & $19(35.2)$ \\
\hline Deceased & $27(52.9)$ & $35(64.8)$ \\
\hline \multicolumn{3}{|l|}{ Number of HLA mismatch } \\
\hline Total & $3.5 \pm 1.9$ & $3.0 \pm 1.6$ \\
\hline DR & $1.1 \pm 0.8$ & $1.0 \pm 0.6$ \\
\hline PRA > 10\%, $n(\%)$ & $11(21.6)$ & $13(24.1)$ \\
\hline \multicolumn{3}{|l|}{ Baseline laboratory data } \\
\hline Creatinine, mg/dL & $1.1 \pm 0.4$ & $1.1 \pm 0.3$ \\
\hline eGFR, $\mathrm{mL} / \mathrm{min} / 1.73 \mathrm{~m}^{2}$ & $69.7 \pm 19.0$ & $74.3 \pm 22.2$ \\
\hline
\end{tabular}

Values are shown as mean \pm standard deviation or number (\%) eGFR estimated glomerular filtration rate, HLA Human leukocyte antigen, $K T$ Kidney transplantation, PRA Panel-reactive antibody

\section{Adherence}

Figure 2 shows dose-taking adherence, dose-frequency adherence, dose-interval adherence, and drug holidays at each period. Patients in both groups had $>98 \%$ adherence throughout the entire study period. The two groups did not significantly differ in adherence, including dosing, time, and drug holidays.

\section{Transplant outcomes between the intervention and control groups}

Table 2 presents transplant outcomes. The intervention and control groups did not significantly differ in the tacrolimus trough levels $(5.3 \pm 1.2$ vs. $5.0 \pm 1.2, p=0.282)$, tacrolimus CV $(23.9 \pm 13.5$ vs. $25.1 \pm 11.4, p=0.645)$, mycophenolic acid trough levels $(2.8 \pm 1.6$ vs. $2.6 \pm 1.3, p=$ $0.600)$, mycophenolic acid CV (37.9 \pm 17.3 vs. $38.9 \pm 19.4$, $p=0.783)$, or renal allograft function at 4 weeks $(67.8 \pm 18.2$ vs. $71.4 \pm 21.8, p=0.365)$ or at 24 weeks $(65.2 \pm 18.9$ vs. $70.2 \pm 21.0, p=0.203)$. Moreover, there was no significant between-group difference in the incidence of development of de novo anti-HLA antibodies (5.9\% vs. $14.8 \%, p=0.135)$. Neither BPAR nor DCGL occurred.

\section{Transplant outcomes according to feedback generation} In the intervention group, a total of 25 significant alarms and feedback messages were generated for 13 KTRs: 17 for missed doses, 6 for dosage errors, and 2 for dosing time errors. The following measurements in the intervention group did not significantly differ according to the number of feedback messages generated: tacrolimus trough levels $(5.1 \pm 1.2$ vs. $5.3 \pm 1.1, p=0.574)$ tacrolimus

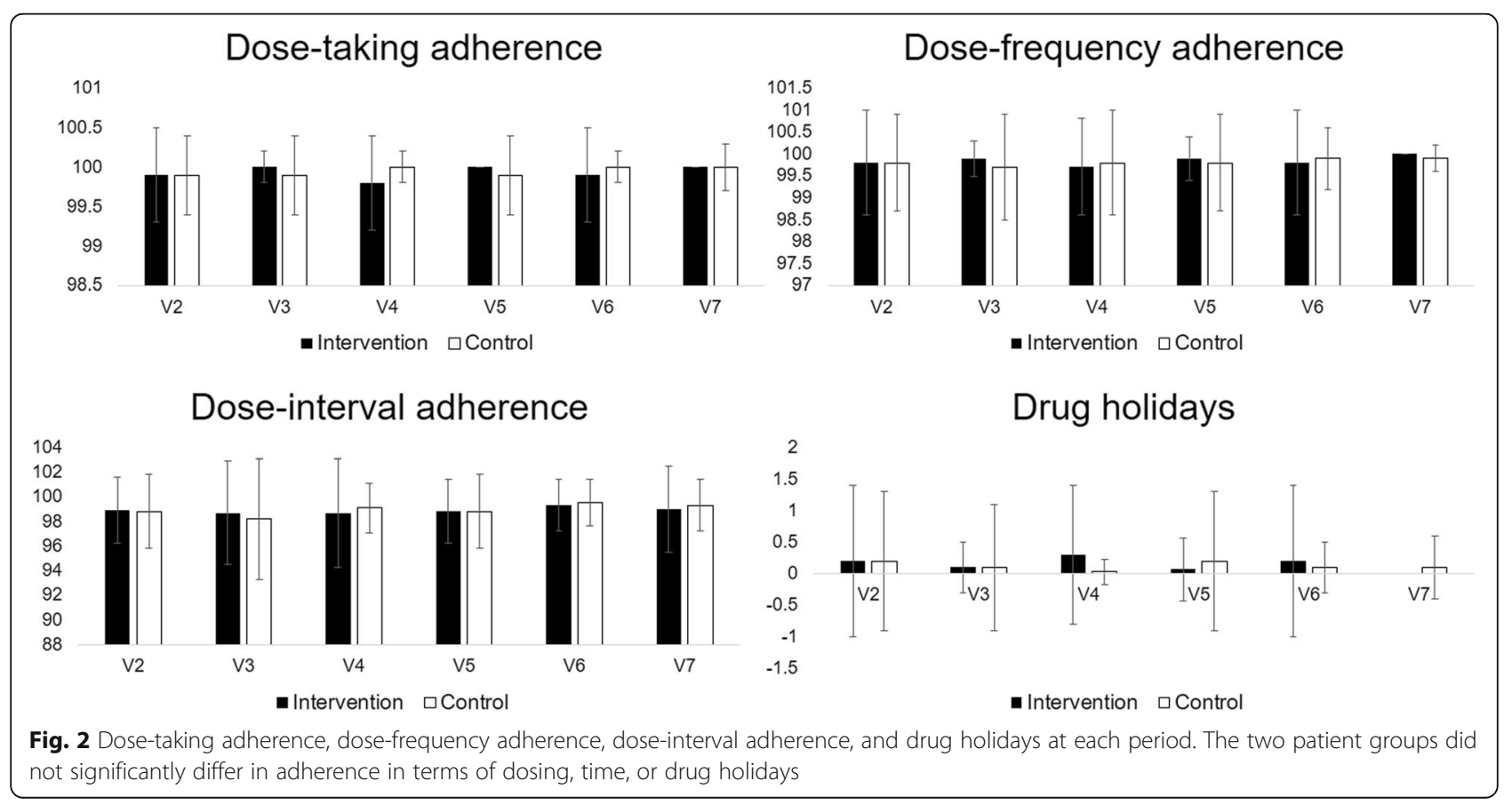


Table 2 Transplant outcomes in the intervention and control groups

\begin{tabular}{|c|c|c|c|}
\hline & Intervention $(n=51)$ & Control $(n=54)$ & $p$ value \\
\hline \multicolumn{4}{|l|}{ Drug levels } \\
\hline TAC trough level, ng/mL & $5.3 \pm 1.2$ & $5.0 \pm 1.2$ & 0.282 \\
\hline TAC CV ${ }^{a}$ & $23.9 \pm 13.5$ & $25.1 \pm 11.4$ & 0.645 \\
\hline MPA trough level, $\mu \mathrm{g} / \mathrm{mL}$ & $2.8 \pm 1.6$ & $2.6 \pm 1.3$ & 0.600 \\
\hline MPA CV ${ }^{a}$ & $37.9 \pm 17.3$ & $38.9 \pm 19.4$ & 0.783 \\
\hline \multicolumn{4}{|l|}{ eGFR } \\
\hline 4 weeks & $67.8 \pm 18.2$ & $71.4 \pm 21.8$ & 0.365 \\
\hline 8 weeks & $67.9 \pm 19.7$ & $71.3 \pm 19.2$ & 0.373 \\
\hline 12 weeks & $66.7 \pm 19.4$ & $71.3 \pm 21.6$ & 0.262 \\
\hline 16 weeks & $67.6 \pm 17.4$ & $72.4 \pm 21.9$ & 0.213 \\
\hline 20 weeks & $66.3 \pm 18.0$ & $71.6 \pm 21.8$ & 0.182 \\
\hline 24 weeks & $65.2 \pm 18.9$ & $70.2 \pm 21.0$ & 0.203 \\
\hline \multicolumn{4}{|l|}{ Number of events, $n(\%)$} \\
\hline De novo anti-HLA antibodies & $3(5.9)$ & $8(14.8)$ & 0.135 \\
\hline BK viremia & $1(2.0)$ & $1(1.9)$ & 1.000 \\
\hline BPAR & - & - & \\
\hline DCGL & - & - & \\
\hline
\end{tabular}

Values are shown as mean \pm standard deviation or number (\%)

BPAR Biopsy-proven acute rejection, CV Coefficient of variation, DCGL Death-censored graft loss, eGFR estimated glomerular filtration rate, HLA Human leukocyte antigen, MPA Mycophenolic acid, TAC Tacrolimus

${ }^{\mathrm{a}} \mathrm{CV}=$ (standard deviation $/$ mean $) \times 100 \%$

Table 3 Transplant outcomes of the intervention group according to the number of feedback messages generated

\begin{tabular}{|c|c|c|c|}
\hline & Feedback $\geq 1 \quad(n=13)$ & No feedback $(n=38)$ & $p$ value \\
\hline \multicolumn{4}{|l|}{ Drug levels } \\
\hline TAC trough level, ng/mL & $5.1 \pm 1.2$ & $5.3 \pm 1.1$ & 0.574 \\
\hline TAC CV ${ }^{\mathrm{a}}$ & $29.4 \pm 16.3$ & $22.1 \pm 12.0$ & 0.155 \\
\hline MPA trough level, $\mu \mathrm{g} / \mathrm{mL}$ & $2.4 \pm 1.0$ & $2.9 \pm 1.8$ & 0.332 \\
\hline $\mathrm{MPACV^{a }}$ & $36.6 \pm 24.8$ & $38.3 \pm 14.3$ & 0.754 \\
\hline \multicolumn{4}{|l|}{ eGFR } \\
\hline 4 weeks & $71.5 \pm 21.9$ & $66.6 \pm 16.9$ & 0.474 \\
\hline 8 weeks & $69.8 \pm 22.7$ & $67.3 \pm 18.8$ & 0.720 \\
\hline 12 weeks & $66.4 \pm 21.0$ & $66.8 \pm 19.1$ & 0.946 \\
\hline 16 weeks & $66.6 \pm 19.4$ & $67.9 \pm 16.9$ & 0.829 \\
\hline 20 weeks & $66.9 \pm 22.2$ & $66.1 \pm 16.6$ & 0.914 \\
\hline 24 weeks & $65.7 \pm 23.5$ & $65.0 \pm 17.4$ & 0.928 \\
\hline \multicolumn{4}{|l|}{ Number of events, $n$ (\%) } \\
\hline De novo anti-HLA antibodies & $1(7.7)$ & $2(5.3)$ & 0.748 \\
\hline BK viremia & $0(0)$ & $1(2.6)$ & 0.555 \\
\hline BPAR & - & - & \\
\hline DCGL & - & - & \\
\hline
\end{tabular}

Values are shown as mean \pm standard deviation or number (\%)

BPAR Biopsy-proven acute rejection, CV Coefficient of variation, DCGL Death-censored graft loss, eGFR estimated glomerular filtration rate, HLA Human leukocyte antigen, MPA Mycophenolic acid, TAC Tacrolimus

${ }^{\mathrm{a}} \mathrm{CV}=($ standard deviation $/$ mean $) \times 100 \%$ 
CV (29.4 \pm 16.3 vs. $22.1 \pm 12.0, p=0.155)$, mycophenolic acid trough levels $(2.4 \pm 1.0$ vs. $2.9 \pm 1.8, p=0.332)$, mycophenolic acid CV $(36.6 \pm 24.8$ vs. $38.3 \pm 14.3, p=0.754)$, renal allograft function at 4 weeks $(71.5 \pm 21.9$ vs. $66.6 \pm$ $16.9, p=0.474)$ and at 24 weeks $(65.7 \pm 23.5$ vs. $65.0 \pm$ $17.4,0.928)$, and the incidence of development of de novo anti-HLA antibodies $(7.7 \%$ vs $5.3 \%, p=0.555)$ (Table 3$)$. Figure 3 shows an example of adherence data in the intervention group as presented in the electronic case report form system. This report allows medical staff to check on the patient's medication use, dosing time, and dosage.

\section{System satisfaction}

Table 4 shows the general information regarding patients who completed the ICT-based clinical trial system satisfaction questionnaire. Of these patients, $50.0 \%$ were in their 50s, $57.1 \%$ were men, and $76.2 \%$ lived in large cities. All patients used a smartphone, and they searched for health information (information about symptoms, medications, etc.) on the Internet or through wireless communications with a mean frequency of 1.8 times per week.

Table 5 shows the patients' satisfaction with the ICTbased clinical trial system. The overall satisfaction with the system was above the median score, and significantly increased across the study period. The patients gave generally positive assessments of the system's convenience, safety, and accuracy, and generally responded positively to the idea of using the system to participate in future clinical trials.

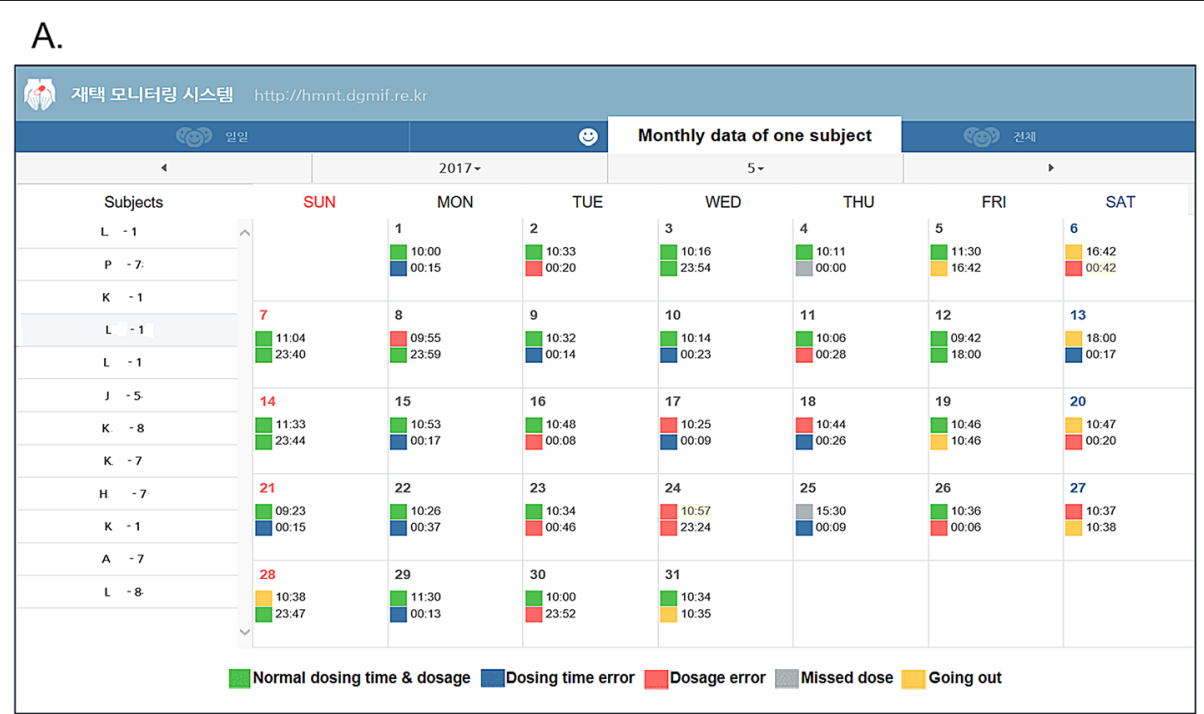

B.

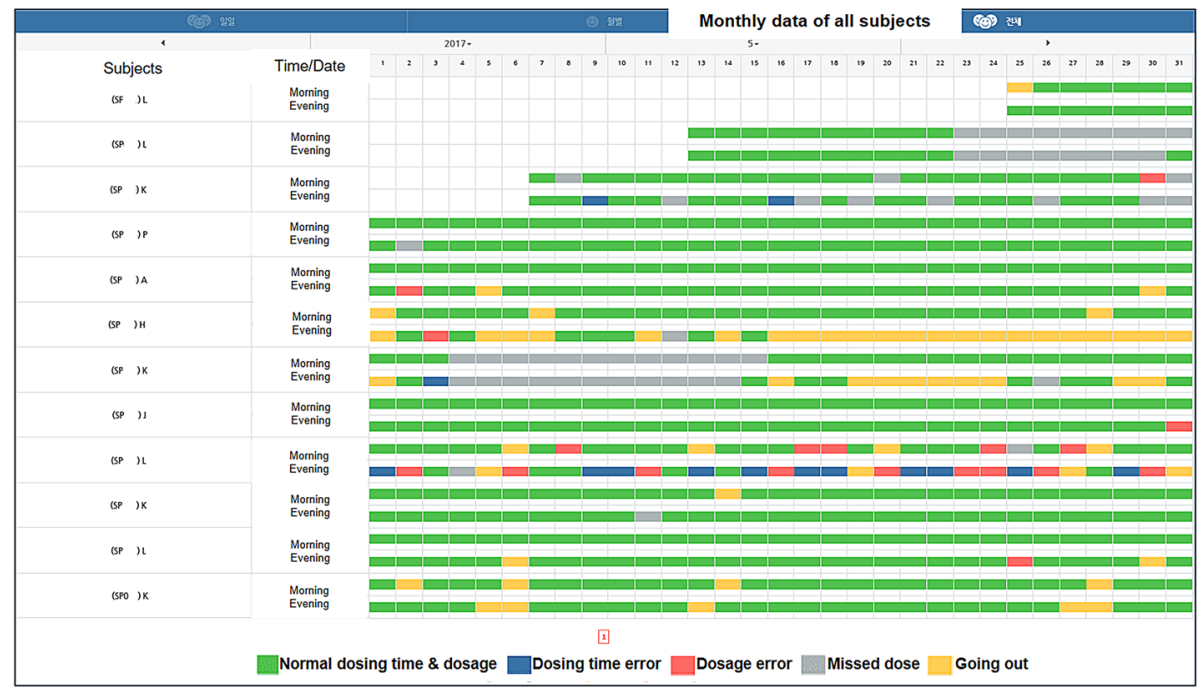

Fig. 3 An example of adherence data in the intervention group as presented in the electronic case report form system. a Monthly data for one subject. b Monthly data for all subjects 
Table 4 General information about patients who completed the ICT-based clinical trial system satisfaction questionnaire

\begin{tabular}{|c|c|}
\hline \multicolumn{2}{|l|}{ Age, $n(\%)$} \\
\hline $20 \mathrm{~s}$ & $2(4.8)$ \\
\hline $30 \mathrm{~s}$ & $2(4.8)$ \\
\hline $40 \mathrm{~s}$ & $9(21.4$ \\
\hline $50 \mathrm{~s}$ & $\begin{array}{l}21 \\
(50.0)\end{array}$ \\
\hline 60 s or above & $8(19.1$ \\
\hline Male, $n(\%)$ & $\begin{array}{l}24 \\
(57.1)\end{array}$ \\
\hline \multicolumn{2}{|l|}{ Education level, $n$ (\%) } \\
\hline Elementary school & $3(7.1)$ \\
\hline Middle school & $6(14.3$ \\
\hline High school & $\begin{array}{l}23 \\
(54.8)\end{array}$ \\
\hline University & $9(21.4$ \\
\hline Above university & $1(2.4)$ \\
\hline \multicolumn{2}{|l|}{ Area of residence, $n$ (\%) } \\
\hline Large city (metropolitan city) & $\begin{array}{l}32 \\
(76.2)\end{array}$ \\
\hline Small- to medium-sized city & $6(14.3$ \\
\hline Agricultural and fishing village & $4(9.2)$ \\
\hline Smartphone use, $n(\%)$ & $\begin{array}{l}42 \\
(100)\end{array}$ \\
\hline $\begin{array}{l}\text { Weekly frequency of searching health information (symptoms, } \\
\text { medications, etc.) on the Internet or though wireless } \\
\text { communications }\end{array}$ & $\begin{array}{l}1.8 \pm \\
1.7\end{array}$ \\
\hline \multicolumn{2}{|l|}{ Occupation, n (\%) } \\
\hline Self-employment & $\begin{array}{l}11 \\
(26.2)\end{array}$ \\
\hline Employee & $7(16.7)$ \\
\hline Agricultural and livestock industry workers & $2(4.8)$ \\
\hline Monk or Pastor & $1(2.4)$ \\
\hline Student & $1(2.4)$ \\
\hline Housewife & $\begin{array}{l}11 \\
(26.2)\end{array}$ \\
\hline Not employed & $9(21.4$ \\
\hline
\end{tabular}

Values are shown as mean \pm standard deviation or number (\%)

\section{Discussion}

In this randomized clinical trial, we found that Korean KTRs already showed high adherence in terms of dosing and timing. The ICT-based centralized monitoring system did not significantly improve adherence to immunosuppressive medications or transplant outcomes in this population. However, the KTRs expressed overall high satisfaction with the ICT-based centralized monitoring system, and this satisfaction significantly improved across the study period. Participants gave an overall positive assessment of the system's convenience, safety, and accuracy. Although this system did not maximize mediation adherence or enhance transplant outcomes in KTRs due to the already high baseline adherence, the high satisfaction indicates that the system could be successfully applied in future clinical trials targeting other disease groups with impaired adherence.

Previous studies have assessed the effects of technologybased adherence-promoting interventions-including the use of electronically monitored drug-dispensing devices or mobile phone applications with feedback (including alarms, text messages, telephone calls, e-mails, or face-toface meeting) - and have demonstrated that such interventions are associated with higher adherence among KTRs or other organ transplant recipients [7-9, 13-16]. Table 6 summarizes recent studies evaluating technology-based adherence-promoting interventions in KTRs. Henriksson et al. tested the use of an electronic medication dispenser for 1 year to improve adherence among KTRs (40 intervention patients, 40 control patients), and reported that the intervention was associated with high adherence [9]. However, unlike our current study, that prior study did not measure adherence in the control group, and did not determine different aspects of adherence, such as dosetaking adherence, dose-frequency adherence, and doseinterval adherence. Reese et al. examined the use of electronic medication monitoring and reminders (including alarms, texts, telephone calls, and/or e-mails) either alone or in combination with provider notification for 6 months among KTRs (40 patients with reminders, 39 with reminders plus provider notification, and 38 control patients), and found that the intervention resulted in significantly better medication dose-taking adherence [8]. While our current study used only text messages and pill box alarms, Reese et al. may have made participants more comfortable with the system by enabling them to choose from customized reminders. In the study of Foster et al., KTRs (81 intervention patients, 88 control patients) received reminders (including text messages, e-mails, and/or visual cues for dose reminders) and had face-to-face meetings with a coach at 3-month intervals over 12 months. Their results demonstrated that the intervention led to significantly better medication dose-taking adherence and dose-frequency adherence [7]. Unlike our present study, that previous study included face-to-face feedback from a coach, which might contribute to different results. On limitation that is shared between previous studies and our present study is that the electronic pill bottles and the smart pill box only measure opening, but do not confirm actual pill ingestion.

With regards to the effects of interventions on transplant outcomes, previous studies have reported conflicting results. We hypothesized that the ICT-based centralized monitoring system could improve medication adherence in KTRs, ultimately inducing stable drug concentrations and thus reducing the development of de 
Table 5 ICT-based clinical trial system satisfaction questionnaire scores

\begin{tabular}{|c|c|c|c|}
\hline & Visit 2 & Visit 7 & $\begin{array}{l}p \\
\text { value }\end{array}$ \\
\hline Are you satisfied with the system, overall? & $3.6 \pm 1.0$ & $3.9 \pm 0.7$ & 0.012 \\
\hline Was the system convenient to use? & $3.6 \pm 0.9$ & $3.8 \pm 0.8$ & 0.294 \\
\hline Was it safe to use the system in the clinical trial? & $4.1 \pm 0.4$ & $4.1 \pm 0.7$ & 0.767 \\
\hline Did use of the system reduce the duration of the trips made to participate in this clinical trial? & $3.4 \pm 0.8$ & $3.4 \pm 0.8$ & 0.499 \\
\hline Did use of the system reduce the inconvenience associated with transportation? & $3.3 \pm 0.8$ & $3.4 \pm 0.8$ & 0.618 \\
\hline Were the researchers able to more accurately assess your condition by using the system? & $4.0 \pm 0.7$ & $3.9 \pm 0.7$ & 0.710 \\
\hline $\begin{array}{l}\text { Did the devices included in the system (fingerprint sensor, home monitoring devices, gateway/smartphone apps, } \\
\text { modem, etc.) provide reliable measurements? }\end{array}$ & $3.8 \pm 0.8$ & $3.9 \pm 0.7$ & 0.844 \\
\hline Were the aforementioned devices easy to use? & $3.9 \pm 0.9$ & $3.9 \pm 0.8$ & 0.872 \\
\hline Are you satisfied with the education regarding directions and precautions for using the aforementioned devices? & $4.2 \pm 0.7$ & $4.1 \pm 0.7$ & 0.183 \\
\hline Are you satisfied with how the researchers handled errors that arose from the aforementioned devices? & $4.3 \pm 0.8$ & $4.3 \pm 0.8$ & 0.200 \\
\hline Total scores & $38.2 \pm 5.8$ & $38.8 \pm 5.5$ & 0.622 \\
\hline \multicolumn{4}{|l|}{ If the ICT-based centralized monitoring system is introduced into this clinical trial, } \\
\hline Will you consistently participate in this clinical trial using the ICT-based centralized monitoring system? & $3.9 \pm 1.0$ & $3.7 \pm 0.8$ & 0.323 \\
\hline $\begin{array}{l}\text { Will you participate in this clinical trial even if it takes place at a hospital located farther away from your home owing } \\
\text { to the availability of the system at that location? }\end{array}$ & $3.3 \pm 1.2$ & $3.1 \pm 1.0$ & 0.648 \\
\hline Was this clinical trial using the system helpful for the management of your health? & $3.9 \pm 0.9$ & $3.9 \pm 0.9$ & 0.578 \\
\hline Will this clinical trial using the system positively contribute to your quality of life? & $3.7 \pm 1.0$ & $3.7 \pm 0.8$ & 0.660 \\
\hline Would you recommend a clinical trial using this system to others? & $3.6 \pm 1.1$ & $3.8 \pm 0.8$ & 0.263 \\
\hline $\begin{array}{l}\text { Do you think clinical trials using the system may lead to any losses or damage associated with personal medical } \\
\text { information leakage? }\end{array}$ & $3.5 \pm 1.0$ & $3.9 \pm 0.9$ & 0.054 \\
\hline $\begin{array}{l}\text { Do you think it will become more difficult to use medical services owing to technical issues associated with the } \\
\text { system? }\end{array}$ & $3.7 \pm 1.0$ & $3.8 \pm 0.8$ & 0.893 \\
\hline Do you think technical issues associated with the system will give rise to medical accidents? & $4.1 \pm 0.8$ & $3.9 \pm 0.9$ & 0.130 \\
\hline Total scores & $29.6 \pm 5.4$ & $29.8 \pm 4.2$ & 0.932 \\
\hline
\end{tabular}

Values are shown as mean \pm standard deviation

Each domain is rated on a scale from 1 to 5 , with higher scores reflecting better satisfaction

novo anti-HLA antibodies, viral infection, and BPAR. Contrary to our expectations, drug adherence, tacrolimus and MPA trough concentrations, drug level variability, and the incidences of development of de novo anti-HLA antibodies, BK viremia, and BPAR did not significantly differ between the ICT-based centralized monitoring group and the control group, or within the intervention group between patients with versus without feedback generation. Compared with previous studies, the KTRs in our present study exhibited considerably higher adherence of $99-100 \%$. Therefore, there was little-to-no room for improvement based on feedback generated from the ICT-based centralized monitoring system. Consequently, we did not observe superior transplant outcomes in the ICT-based centralized monitoring group compared with the control group, or in the patients with versus without feedback generation within the intervention group.

Although we did not find that the monitoring system led to improved adherence due to the already high baseline adherence in Korean KTRs, this study has several strengths and the results have clinical implications. First, to our knowledge, this is the first study to investigate the adherence of Korean KTRs with continuous use of an ICT-based centralized monitoring system. Moreover, it is the first clinical study to provide data regarding medication adherence among Korean KTRs. The higher adherence observed in Korean KTRs compared to in KTRs in other countries could be partly due to the national health insurance coverage system for transplant recipients in South Korea. Out present data suggest that the proportion of non-adherence leading to antibodymediated rejection may differ among countries [1], and that the causes of renal allograft loss may also differ. This indicates that different and additional immunological strategies may be required to improve renal allograft survival in different countries. Second, the overall satisfaction with the system was higher than neutral, even though most users were in their 50s or older. This suggests that the ICT-based centralized monitoring system could be applied to other diseases, such as recipients of other organ transplants, or patients with hypertension, diabetes, 


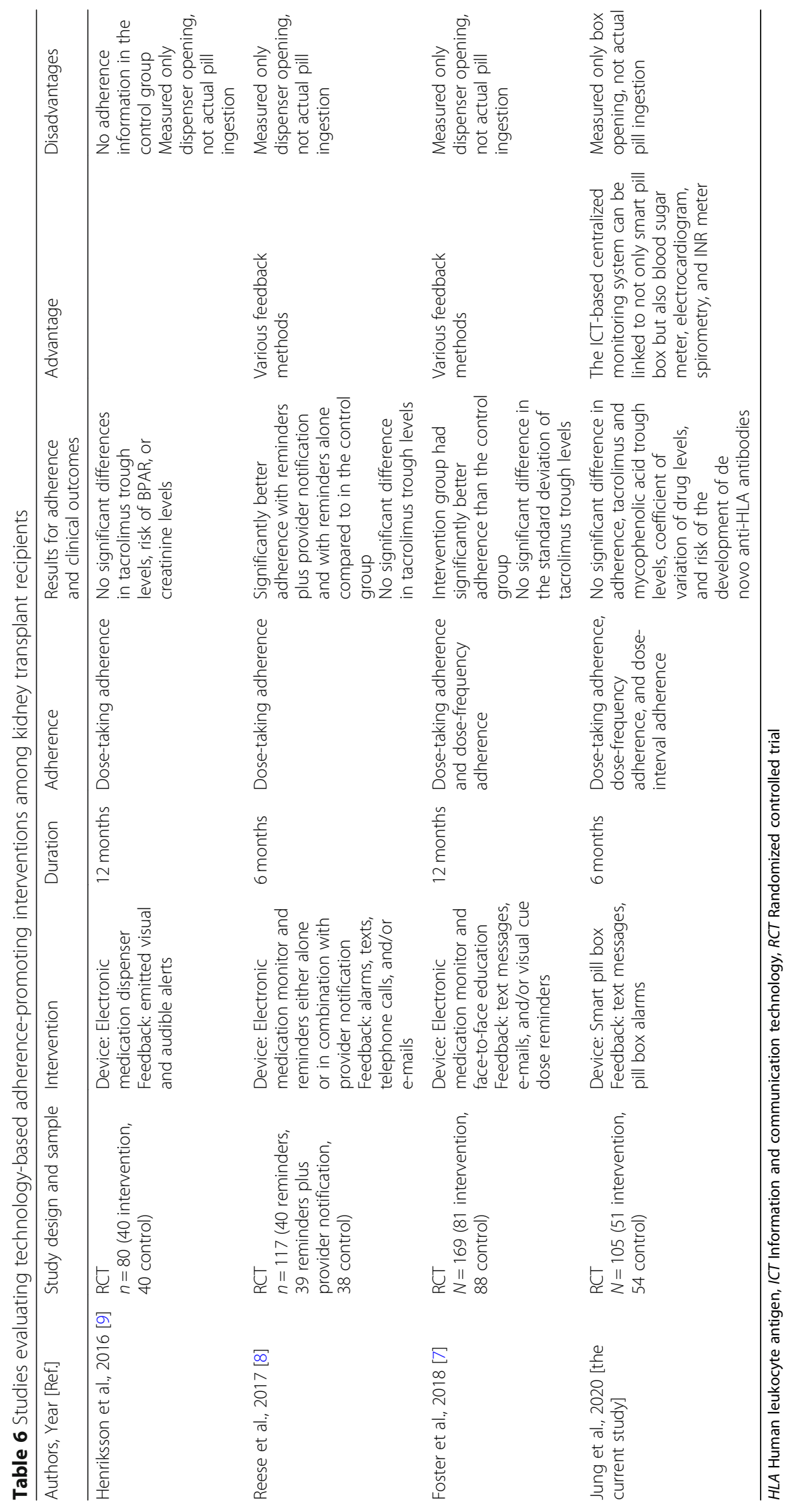


chronic kidney disease, cardiovascular disease, human immunodeficiency virus infection, dementia, and tuberculosis. Moreover, the high satisfaction with the ICT-based clinical trial could pave the way for establishing an ICT-based centralized monitoring system for future clinical trials. Further system validation will be necessary to expand the use of this monitoring system in future clinical trials.

\section{Conclusions}

In conclusion, in our present study, the ICT-based centralized monitoring system did not improve mediation adherence or transplant outcomes in Korean KTRs due to the already high baseline adherence. However, we found high patient satisfaction with the system in terms of convenience, safety, and accuracy. This suggests that the ICT-based centralized monitoring system could be successfully used in future clinical trials targeting other disease groups with impaired adherence and in which medication adherence critical to the course of treatment.

\section{Advantages and disadvantages}

Through this clinical trial, we identified the following advantages and disadvantages of the ICT-based centralized monitoring system. First, this system enabled us to receive real-time information on adherence collected through the smart pill box, check this information using an electronic case report form system, and provide patients with real-time feedback regarding dose, frequency, and interval. This enabled medical staff to identify patients' patterns and exact times of taking medicines, and helped them understand the levels of immunosuppressive agents in the outpatient clinic. Second, the ICT-based centralized monitoring system could be linked to not only the smart pill box but also to a blood sugar meter, electrocardiogram, spirometry, and INR meter. Therefore, a strength of this system is that it can be successfully used in other diseases that require constant monitoring due to severe fluctuations in symptoms or results. Third, like recent studies that have introduced systems that collect current information and predict future trends [17-20], once our adherence-related information is accumulated, it will also be available to predict future patterns of adherence in KTRs. Forth, some patients experienced technical problems, such as failed fingerprint recognition or incorrect reminders while they were out. However, these technical issues were all resolved early in the study. Fifth, in areas with inconsistent Internet communication, there may be problems with data transmission.

\section{Supplementary information}

Supplementary information accompanies this paper at https://doi.org/10. 1186/s12911-020-01146-6.

\section{Additional file 1.}

\section{Abbreviations}

BPAR: Biopsy-proven acute rejection; CV: Coefficient of variation;

DCGL: Death-censored graft loss; eGFR: estimated glomerular filtration rate;

ICT: Information and Communication Technology; KTRs: Kidney transplant recipients; PRA: Panel-reactive antibody; RCT: Randomized controlled trial

\section{Acknowledgements}

Not applicable.

\section{Authors' contributions}

$\mathrm{HYJ}$ contributed to the study design and wrote the paper. YJ contributed to data analysis. SJS and YRY contributed to the establishment of the system.

JJS participated in correcting the protocol. JYC, JHC, SHP, and CDK participated in study subject recruitment. SHY and JSL participated in correcting the protocol and study subject recruitment. YLK contributed to the study design, and made critical revisions of the article for important intellectual content. All authors read and approved the final manuscript.

\section{Funding}

This work was supported by the Technology Innovation Program, 10059066, Establishment of ICT Clinical Trial System and Foundation for Industrialization funded by the Ministry of Trade, Industry \& Energy (MOTIE, Korea). The funders had no role in study design, data collection and analysis, decision to publish, or preparation of the manuscript.

\section{Availability of data and materials}

Data supporting the findings of the current study are available from the corresponding author upon reasonable request.

\section{Ethics approval and consent to participate}

All patients provided their written informed consent before participating in the study, and the study protocol was approved by the Daegu Joint Institutional Review Board (DGIRB 2016-08-010). When enrolling participants under the age of 16 years, written informed consent was provided by the parent or guardian. All clinical investigations were conducted in accordance with the guidelines of the Declaration of Helsinki and the Good Clinical Practice guidelines. The present study adheres to CONSORT guidelines.

\section{Consent for publication}

Not applicable.

\section{Competing interests}

The authors declare that they have no competing interests.

\section{Author details}

${ }^{1}$ Division of Nephrology, Department of Internal Medicine, School of Medicine, Kyungpook National University, Kyungpook National University Hospital, Daegu 41944, South Korea. ${ }^{2}$ Department of Statistics, Kyungpook National University, Daegu, South Korea. ${ }^{3}$ Department of Biomedical Science and Clinical Trial Center, Kyungpook National University, Kyungpook National University Hospital, Daegu, South Korea. ${ }^{4}$ Department of Internal Medicine, Konyang University College of Medicine, Daejeon, South Korea. ${ }^{5}$ Department of Internal Medicine, University of Ulsan College of Medicine, Ulsan, South Korea.

Received: 25 January 2020 Accepted: 3 June 2020

Published online: 10 June 2020

\section{References}

1. Sellares J, de Freitas DG, Mengel M, Reeve J, Einecke G, Sis B, Hidalgo LG, Famulski K, Matas A, Halloran PF. Understanding the causes of kidney transplant failure: the dominant role of antibody-mediated rejection and nonadherence. Am J Transplant. 2012;12(2):388-99. https://doi.org/10.1111/j. 1600-6143.2011.03840.x. 
2. Nevins TE, Nickerson PW, Dew MA. Understanding medication nonadherence after kidney transplant. J Am Soc Nephrol. 2017;28(8):2290301. https://doi.org/10.1681/ASN.2017020216.

3. Pinsky BW, Takemoto SK, Lentine KL, Burroughs TE, Schnitzler MA, Salvalaggio PR. Transplant outcomes and economic costs associated with patient noncompliance to immunosuppression. Am J Transplant. 2009;9(11): 2597-606. https://doi.org/10.1111/j.1600-6143.2009.02798.x.

4. Weng FL, Chandwani S, Kurtyka KM, Zacker C, Chisholm-Burns MA, Demissie K. Prevalence and correlates of medication non-adherence among kidney transplant recipients more than 6 months posttransplant: a cross-sectional study. BMC Nephrol. 2013;14:261. https:// doi.org/10.1186/1471-2369-14-261.

5. Joost R, Dorje F, Schwitulla J, Eckardt KU, Hugo C. Intensified pharmaceutical care is improving immunosuppressive medication adherence in kidney transplant recipients during the first post-transplant year: a quasiexperimental study. Nephrol Dial Transpl. 2014;29(8):1597-607. https://doi. org/10.1093/ndt/gfu207.

6. Patzer RE, Serper M, Reese PP, Przytula K, Koval R, Ladner DP, Levitsky JM, Abecassis MM, Wolf MS. Medication understanding, non-adherence, and clinical outcomes among adult kidney transplant recipients. Clin Transpl. 2016;30(10):1294-305. https://doi.org/10.1111/ctr.12821.

7. Foster BJ, Pai ALH, Zelikovsky N, Amaral S, Bell L, Dharnidharka VR, Hebert D, Holly C, Knauper B, Matsell D, et al. A randomized trial of a multicomponent intervention to promote medication adherence: the teen adherence in kidney transplant effectiveness of intervention trial (TAKE-IT). Am J Kidney Dis. 2018;72(1):30-41. https://doi.org/10.1053/j.ajkd.2017.12.012.

8. Reese PP, Bloom RD, Trofe-Clark J, Mussell A, Leidy D, Levsky S, Zhu J, Yang $L$, Wang W, Troxel A, et al. Automated reminders and physician notification to promote immunosuppression adherence among kidney transplant recipients: a randomized trial. Am J Kidney Dis. 2017;69(3):400-9. https://doi. org/10.1053/j.ajkd.2016.10.017.

9. Henriksson J, Tyden $\mathrm{G}$, Hoijer J, Wadstrom J. A prospective randomized trial on the effect of using an electronic monitoring drug dispensing device to improve adherence and compliance. Transplantation. 2016;100(1):203-9. https://doi.org/10.1097/Tp.0000000000000971.

10. Jung HY, Seong SJ, Choi JY, Cho JH, Park SH, Kim CD, Yoon YR, Kim HK, Huh $\mathrm{S}$, Yoon SH, et al. The efficacy and stability of an information and communication technology-based centralized monitoring system of adherence to immunosuppressive medication in kidney transplant recipients: study protocol for a randomized controlled trial. Trials. 2017;18(1): 480. https://doi.org/10.1186/s13063-017-2221-z.

11. Rodrigo E, Segundo DS, Fernandez-Fresnedo G, Lopez-Hoyos M, Benito A, Ruiz JC, de Cos MA, Arias M. Within-patient variability in Tacrolimus blood levels predicts kidney graft loss and donor-specific antibody development. Transplantation. 2016;100(11):2479-85. https://doi.org/10.1097/TP. 0000000000001040.

12. Vanichanan J, Udomkarnjananun S, Avihingsanon $Y$, Jutivorakool K. Common viral infections in kidney transplant recipients. Kidney Res Clin Pract. 2018;37(4):323-37. https://doi.org/10.23876/j.krcp.18.0063.

13. Low JK, Manias E, Crawford K, Walker R, Mulley WR, Toussaint ND, Dooley M, Kennedy E, Smith CL, Nalder M, et al. Improving medication adherence in adult kidney transplantation (IMAKT): a pilot randomised controlled trial. Sci Rep. 2019;9(1):7734. https://doi.org/10.1038/s41598-019-44002-y.

14. Dobbels F, De Bleser L, Berben L, Kristanto P, Dupont L, Nevens F, Vanhaecke J, Verleden G, De Geest S. Efficacy of a medication adherence enhancing intervention in transplantation: the MAESTRO-Tx trial. J Heart Lung Transplant. 2017;36(5):499-508. https://doi.org/10.1016/j.healun.2017. 01.007.

15. Zanetti-Yabur A, Rizzo A, Hayde N, Watkins AC, Rocca JP, Graham JA. Exploring the usage of a mobile phone application in transplanted patients to encourage medication compliance and education. Am J Surg. 2017; 214(4):743-7. https://doi.org/10.1016/j.amjsurg.2017.01.026.

16. Miloh T, Annunziato R, Arnon R, Warshaw J, Parkar S, Suchy FJ, lyer K, Kerkar N. Improved adherence and outcomes for pediatric liver transplant recipients by using text messaging. Pediatrics. 2009;124(5):E844-50. https:// doi.org/10.1542/peds.2009-0415.

17. Al-Janabi S, Mohammad M, Al-Sultan A. A new method for prediction of air pollution based on intelligent computation. Soft Comput. 2020;24(1):661-80. https://doi.org/10.1007/s00500-019-04495-1.
18. Patel A, Al-Janabi S, AlShourbaji I, Pedersen J. A novel methodology towards a trusted environment in mashup web applications. Comput Secur. 2015:49: 107-22. https://doi.org/10.1016/j.cose.2014.10.009.

19. Al-Janabi S, Mahdi MA. Evaluation prediction techniques to achievement an optimal biomedical analysis. Int J Grid Util Comp. 2019;10(5):512-27.

20. Al-Janabi S, Alkaim AF. A nifty collaborative analysis to predicting a novel tool (DRFLLS) for missing values estimation. Soft Comput. 2020;24(1):555-69. https://doi.org/10.1007/s00500-019-03972-x.

\section{Publisher's Note}

Springer Nature remains neutral with regard to jurisdictional claims in published maps and institutional affiliations.

\section{Ready to submit your research? Choose BMC and benefit from:}

- fast, convenient online submission

- thorough peer review by experienced researchers in your field

- rapid publication on acceptance

- support for research data, including large and complex data types

- gold Open Access which fosters wider collaboration and increased citations

- maximum visibility for your research: over $100 \mathrm{M}$ website views per year

At $\mathrm{BMC}$, research is always in progress.

Learn more biomedcentral.com/submissions 